ISSN 1112-9867

Available online at http://www.jfas.info

\title{
CHRONIC DEHYDRATION AFFECTS HYDROELECTROLYTIC EQUILIBRIUM AND ADRENAL GLAND MORPHOLOGY IN WISTAR RAT: COMPARISON WITH GERBILLUS TARABULI
}

\begin{abstract}
A. Dekar-Madoui*, S. Aouichat, H. Touati and S. Ouali-Hassenaoui
University of Sciences and Technology "Houari Boumediene", Faculty of Biological Sciences, Laboratory of Biology and Physiology of organisms, Neurobiology team, Algiers,
\end{abstract} Algeria

Received: 03 October 2016 / Accepted: 18 April 2017 / Published online: 01 May 2017

\begin{abstract}
Shortage of water supply is the most stressful condition that can meet man and animals. Since the adrenal gland plays a pivotal role in the stress response, the objective of this work is to study, in the male Wistar rat, the repercussions of chronic dehydration on adrenal gland structure compared to that of a desert rodent: Gerbillus tarabuli. Adults and male Wistar rats and gerbils were divided into: i) control rats $(n=8)$ given free access to tap water); ii) dehydrated rats $(\mathrm{n}=8)$ given $2 \% \mathrm{NaCl}$ solution ad libitum for 7 days and (iii) G.tarabuli $(\mathrm{n}=6)$ given barely seeds ad libitum without access to water. Chronic dehydration caused strong adreno-chromaffin cells degranulation in rats. For the gerbils, adrenal zona fasciculate and medulla features suggest respectively an increased production and release of glucocorticoides but a basal stress hormones release. These results suppose that shortage of water in arid environment does not represent a stress factor for this species.
\end{abstract}

Key words: adrenal gland; chronic dehydration; plasmatic parameters; histology; Wistar rat; Gerbillus tarabuli

Author Correspondence, e-mail: aicha.dekar@gmail.com doi: http://dx.doi.org/10.4314/jfas.v9i2.18 


\section{INTRODUCTION}

Water Shortage is one of the most stressful conditions that can meet man and animal. Rodents are considered highly suitable animals for rising in arid and desert regions. They can survive in particularly difficult conditions of water shortage and may go into a dehydration state for a long period during the dry summer season [1]. Numerous research programmes have dealt with the mechanisms of water and electrolyte balance conservation in these wild rodents [2-34-5]. In this study we raise the question whether such extreme conditions constitute a stress factor for their organism. Adrenal gland plays an essential role in adaptative responses and is called stress gland [6]. Any stress increases organism's requirement for glucocorticoides [7] and catecholamines [8-9]. This hormone secretion often increases greatly in stressful situation which is a beneficial situation to the animal as it has life saving role. Taking all this into consideration, we have targeted the study of this sensitive organ in Gerbillus tarabuli a desert rodent of Algeria. It is nocturnal and granivorous, eating mostly leaves. This species can survive exclusively on a dry diet and be independent of exogenous water. Under such arid environment, it seems interesting to investigate its adrenal gland morphology and compare it with that of Wistar rat subjected to chronic dehydration.

\section{MATERIALS AND METHODS}

Adult male Wistar rat (200-250 g weight) (supplied by Institut Pasteur, Kouba, Algiers) and wild Gerbillus tarabuli species (30-53 g weight) captured from March to June in the Algerian Arid Zones Station (Beni Abbès, $1240 \mathrm{Km}$ Southwest of Algeria) served in this study. All animals were kept under standard conditions of temperature $\left(22 \pm 1^{\circ} \mathrm{C}\right)$ and a $12: 12 \mathrm{~h}$ lightdark cycle (light on at 7.00 A.M). Wistar rats were provided with standard rat chow and water ad libitum, and Gerbillus tarabuli were given barely seeds; water had not been supplied. All performed manipulations were in agree with local and international guidelines on ethical use of animals.

\section{Experimental design}

The animals were separated into three groups: (i) Control rat $(n=8)$ were given free access to tap water; (ii) dehydrated rats $(\mathrm{n}=8)$ were given $2 \% \mathrm{NaCl}$ solution as a sole source of their fluid intake, ad libitum, for 7 days; (iii) G.tarabuli (n=6) were given barely seeds ad libitum; water has not been supplied.

Ingestion of $2 \% \mathrm{NaCl}$ solution for 7 days was used as an alternative method of "dehydration" [10]. 
Body weight of all animals was recorded at the beginning and at the end of the experiment. At the end of the experiment (the $8^{\text {th }}$ day), the animals were sacrificed by decapitation without anesthesia between 8 and 11 A.M.

\section{Blood samples determination}

After decapitation, strunk blood was collected promptly into chilled tubes containing heparin for the measurement of osmolality and sodium concentration and into heparinzed microhematocrit capillary tubes for measurement of hematocrit. After centrifugation at $3000 \mathrm{~g}$ for 15 min, plasma samples were aliquoted and stored frozen at $-80^{\circ} \mathrm{C}$ until measurements of osmolality and sodium concentration using an osmometer (Loser type 6) and ionometer respectively. Hematocrit was immediately determined.

\section{Light microscopy}

Both adrenal glands of each animal were quickly removed. Each gland was immersed in each of the following fixative solutions: i) Bouin's solution to detect any morphological changes; ii) Ciaccio solution to demonstrate the changes in the lipids content of adrenal cortex. The materials were then embedded in paraffin, according to standard procedure and cut into $5 \mu \mathrm{m}$ thick sections. Masson trichrome was used as topographic stain and Sudan black B stain for lipid revelation.

\section{Statistical Analysis}

The data are expressed as the mean \pm SEM. For a comparison between the three groups (control rats, dehydrated rats and G.tarabuli), unpaired Student's t-test was used. Statistical significance was accepted at a value of $P \quad 0.05$.

\section{RESULTS}

\section{Body weight}

Our result showed that body weight decreased significantly $(\mathrm{P} 0.01 ;-21.4 \%)$ in rats subjected to chronic dehydration, whereas it did not change significantly in the control rats (P $0.05 ;+2.5 \%$ ) and G.tarabuli (P $0.05 ;+0.6 \%$ ) (Table 1$)$.

Table 1. Body weight in control rats, dehydrated rats and Gerbilus tarabuli

\begin{tabular}{|c|c|c|c|}
\hline & Initial body weight & Final body weight & BW\% \\
\hline Control rat $(\mathrm{n}=8)$ & $244.2 \pm 11.1$ & $249.5 \pm 10.1$ & $2.5 \%$ \\
\hline Dehydrated rat $(\mathrm{n}=8)$ & $250.2 \pm 9.3$ & $196.6 \pm 13.2^{* *}$ & $21.4 \%$ \\
\hline G.tarabuli $(\mathrm{n}=6)$ & $44.4 \pm 3.5$ & $44.7 \pm 3.57$ & $0.6 \%$ \\
\hline
\end{tabular}

Values are means \pm SEM. $* * P 0.01$. Final weight $v s$ initial weight. BW $(\%)=(\mathrm{BW}$ final BW initial/BW initial).100. 


\section{Hematocrit, Plasma Osmolality, and plasma sodium}

The mean value of hematocrit was higher in the dehydrated rats than in the control rats (P 0.001). This value was lower in G.tarabuli ( $\mathrm{P}$ 0.001) than in the control rats. In contrast, plasma osmolality was quite similar in G.tarabuli and dehydrated rats, but significantly lower in control rats. Plasma sodium of G.tarabuli was lower (P 0.001) than that of dehydrated rats (Table 2).

Table 2. Blood parameters in control rats, dehydrated rats and Gerbilus tarabuli

\begin{tabular}{|c|c|c|c|}
\hline & Control rat $(\mathrm{n}=8)$ & dehydrated rat $(\mathrm{n}=8)$ & G.tarabuli $(\mathrm{n}=6)$ \\
\hline Hematocrit (\%) & $45.1 \pm 0.1$ & $50.7 \pm 0,3^{* * * *}$ & $35.8 \pm 0,7^{* * *+\dagger}$ \\
\hline $\begin{array}{c}\text { osmolality } \\
(\mathrm{mOsm} / \mathrm{kg} \mathrm{H} 2 \mathrm{O})\end{array}$ & $294.3 \pm 0.9$ & $317.2 \pm 0,8^{* * *}$ & $314.4 \pm 1,2^{* * *}$ \\
\hline $\mathrm{Na}^{+}(\mathrm{mEquiv} / \mathrm{L})$ & $133.7 \pm 0.2$ & $150.3 \pm 0,3^{* * * *}$ & $145.7 \pm 0,4^{* * *+\dagger}$ \\
\hline
\end{tabular}

Values are means \pm SEM. $* * * P<0.001 v s$. Control; $\dagger \dagger \dagger P<0.001 v s$. Dehydrated.

\section{Light microscopy}

Analysis of Masson trichrome stained sections revealed that zona fasciculata (ZF) of control rats (Fig.1A) were composed of polyhedral cells arranged in long straight cords separated by narrowed blood capillaries. The cells showed abundant foamy cytoplasm with pale rounded nuclei and distinct nucleoli. In the dehydrated rats (Fig.1B) as in G.tarabuli (Fig.1C), our observation showed that ZF was characterized by a marked dilated blood capillaries and an acidophilic cytoplasm. The arrangement of cells in long straight cords was not evident in G.tarabuli (Fig.1C). The intensity of the Sudan black B reaction was more pronounced in control rat (Fig.1D), as compared to both dehydrated rat (Fig.1E) and G.tarabuli (Fig.1F).

The examination of sections from control rats (Fig.2A) and gerbils (Fig.2E) showed the typical structure of adrenal medulla. Chromaffin cells were arranged in closely packed clusters separated by delicate connective tissue containing blood sinusoids. They were polyhedral in shape, with deeply stained granular cytoplasm and rounded pale nuclei.

In the dehydrated rat, cell disposition was completely disturbed. Most of the chromaffin cells appeared hypertrophied with poorly defined cell boundaries. Their cytoplasm was pale indicating degranulation. Several nuclei were pyknotic (Fig. 2B). Also, abnormal interstitial fibrosis (Fig. 2C) and numerous enlarged blood sinusoids (Fig. 2D) were seen. 

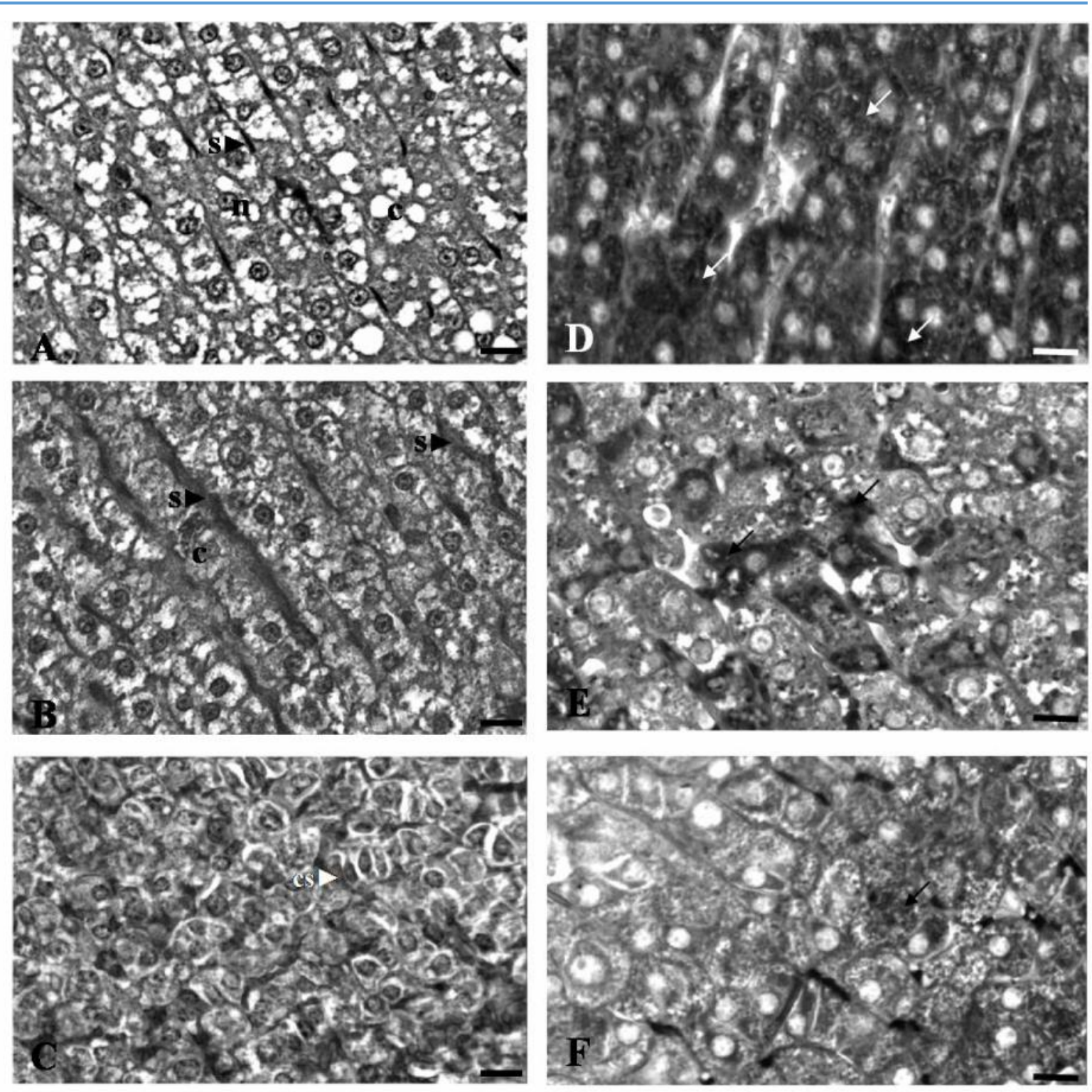

Fig.1. Zona fasciculata:

In control rat (A) The ZF cells are arranged in long radial cords separated by narrowed blood capillaries (s). They have abundant cytoplasm (c) with a foamy appearance and fairly rounded pale nuclei (n). In dehydrated rat (B) note the disappearance of the foamy appearance of cytoplasm (c) and dilated blood sinusoids (s). In G.trabuli (C), The arrangement of cells in long radial cords is not evident, lipid droplets are scarce and blood sinusoids are dilated (s).

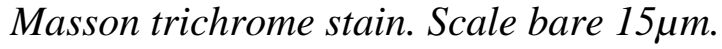

Sudan black B staining of zona fasciculata in control rat (D) show numerous sudanophile cytoplasmic inclusions (arrow). Note the less pronounced sudanophilia in dehydrated rat (E) and G.trabuli (F). Scale bare $12 \mu \mathrm{m}$. 

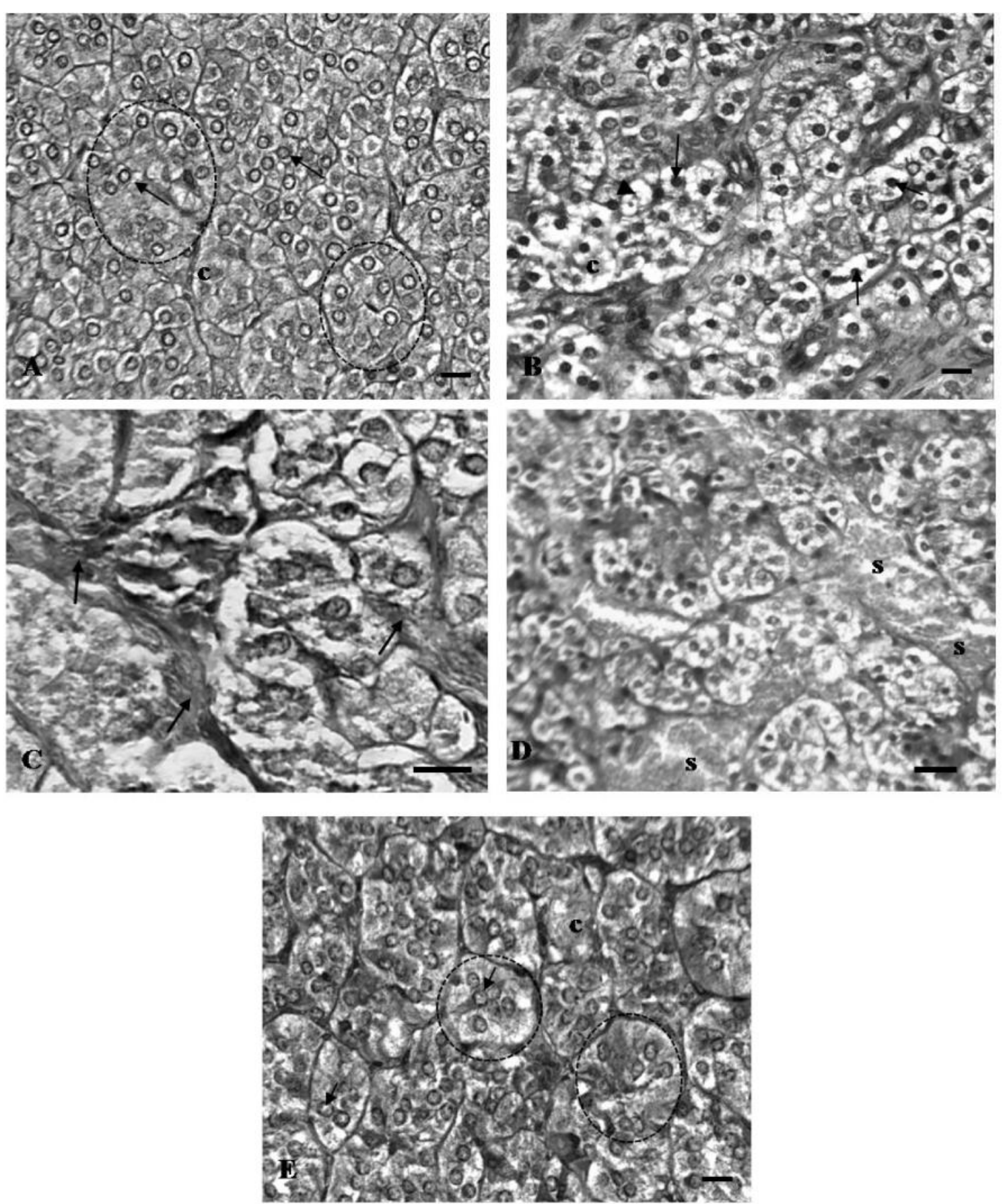

Fig.2. Adrenal medulla:

In control rat (A) and G.trabuli (E), chromaffin cells are arranged in packed clusters (dotted

line). They are polyhedral in shape with finely granulated cytoplasm (c) and rounded vesicular nuclei (arrow). Masson trichrome stain. Scale bare $15 \mu \mathrm{m}$. In dehydrated rat (B) the cell arrangement is disturbed and most of cells are hypertrophied with poorly defined cell boundaries. Cytoplasms (c) are completely degranulate and appear vacuolated (arrowhead).

Some nuclei are Pykcnotic (arrow). Parallaly in this group we can see (C) an abnormal fibrotic mass (arrow) and (D) numerous dilated blood sinusoids (s) engorged with stagnant blood cells. Masson trichrome stain. Scale bare $15 \mu \mathrm{m}$ 


\section{DISCUSSION}

The current study revealed that chronic dehydration in Wistar rats produces a dramatic loss in body weight. This finding is in agreement with previous studies [11-12-13]. The weight lost recorded in dehydrated rats can be attributed to the reduced body fluids, as it was estimated by Van Bauman's formula (result not shown), and partially to a reduction in food consumption (personnel observations), which leads ultimately to tissue catabolism. Indeed, our observation is supported by experimental evidence showing that rats submitted to similar conditions developed anorexia [14-15].

Like rats under control conditions, our desert rodent G.tarabuli did not show any significant difference between final and initial body weight. There is evidence that desert rodents are able to maintain body weight on diet of only dry seeds [3-16-17].

In rats subjected to chronic dehydration, a significant increase in blood variables (hematocrit, plasma osmolality and plasma sodium concentration) was noted. This is clearly in favour of hydroelecrolytic imbalance and hemoconcentration. Our results in G.tarabuli showed that plasma osmolality was close to that measured in dehydrated rats, while hematocrit was significantly lower than in control rats. This suggests that the blood of $G$. tarabuli contains more water than that of Wistar rat, since hematocrit has been shown as a reliable indicator of plasma volume [18].

Upon histological examination, important modifications were observed in rats exposed to chronic dehydration. In zona fasciculata, the most striking change is the enlargement of blood capillaries and depletion of lipid droplets, as proved by Sudan black B stain. The lipid droplets are the site of cholesterol storage [19]. Their mobilization and hydrolysis by the cholesterol ester hydrolase enzyme stimulates the biosynthesis of steroid hormones such as glucocorticoides [20]. The lipid droplets depletion can be explained by the fact that the novo cholesterol synthesis and the uptake of lipoprotein-derived cholesterol via low density lipoprotein receptor could not overcome its utilization in steroidogenesis, so lipid depletion occurred. These histological changes in ZF seem to be in favour of an excessive glucocorticoids biosynthesis as an adaptative response to the stress situation caused by the alteration of hydroelecrolytic equilibrium. Our suggestion is supported by previous study showing that receiving $2 \%$ saline as drinking fluid during 7 days caused a marked increase in plasma corticosterone concentration in Wistar rats [21]. In adrenal medulla of dehydrated rats, marked degranulation of chromaffin cells and enlargement of blood sinusoids were observed. This seems to reflect a strong catecholamines release. Such a degranulation of chromaffin cells has been also observed in rat after various stressors [7-22]. Also, signs of cell 
degeneration were evidenced in chromaffin cells displayed by hypertrophy of cells with loss of cell borders, vacuolation of cytoplasm, and pyknotic nuclei. This could be due to hyperactivity of these cells for secreting more and more catecholamines to adapt with stress situation, which exceeded the adaptation capacity of chromaffin cells leading to the cell death. Our results in G.tarabuli showed that the adrenal medulla exhibited the same morphological features as those observed in Wistar rat under control conditions, despite the high plasma osmolality, known as a potent stressor. In contrast, the structure of $\mathrm{ZF}$ is rather well comparable to that of dehydrated rat, suggesting a potent steroidogenesis activity to produce great amonts of glucocorticoids. Indeed, it was found (not bublished results) that the plasma level of the primary glucocorticoid (cortisol) in G. tarabuli was comparatively high $(292 \pm 51$ $\mathrm{ng} / \mathrm{ml}$ ), with the same essay method the plasma corticosterone levels in laboratory rat under basal conditions had been estimated to $28.8 \pm 7.9 \mathrm{ng} / \mathrm{ml}$ [23]. In their interesting study Wotus et al, 2007 have shown a positive correlation between plasma levels of corticosterone and the hypothalamic hormone, vasopressin (AVP) in dehydrated rats [24]. This evidence may constitute another argument in favour of a potent steroidogenesis activity; bearing in mind that plasma AVP concentrations were higher in desert rodents than in laboratory rats, as was shown by previous studies [25-3]. Considering the result obtained, we raise the question of whether such morphological characters observed in ZF of G.tarabuli, reflect stress response. It is difficult to find a fully satisfactory explanation, since we have noted contradictory results in G.tarabuli, on one hand, the structure of ZF is similar to that of dehydrated rat and on the other hand the structure of adrenal medulla is comparable to that of control rat. Several explanations could be hypothesized: i)-the structure of ZF might reflect stress response in order to adapt to the shortage of water, which characterize the extremely arid biotope. Thus, the histological structure of adrenal medulla, comparable to that of rat under basal condition, could mean that chromaffin cells may have an important catecholamine biosynthesis rate, which permits the restoration of catecholamines stores. ii)-the structure of adrenal medulla might indicate a basal stress hormones release. This prompts us to hypothesize for the first time that the morphological features of ZF, in favour of hyperactivity, would not be a stress response but rather an index of metabolic strategy probably for metabolic water production. 


\section{CONCLUSION}

This study revealed that chronic dehydration produces, in Wistar rat, a condition of stress which exceeded the adaptation capacity of adrenal medulla leading to the depletion. In $G$. tarabuli, however, it remains unclear whether the morphological characteristics observed in adrenal medulla represent tolerance following persistent stress stimulation or, the poverty in water, which characterizes the arid environment, does not represent a stress situation for this wild species.

\section{REFERENCES}

[1] Tirado C,Cortes A, Bozinovic F. Water balance in two South American Phyllotis desert rodents, P. xanthopygus rupestris and P. darwini darwini. J. Arid Environ., 72, 2008, 664-670. [2] Göransson V, Johnsson C, Nylander O, Hansell P. Renomedullary and intestinal hyaluronan content during body water excess: a study in rats and . Journal of Physiology, 2002, 542(1), 315-322.

[3] Sellami A, Maurel D, Kosa E, Siaud P. Réponses hormonales du mérion, un rongeur désertique à la privation d'eau prolongée: comparaison avec le rat. Mesogee 61, 2005, 7-15.

[4] Lacas S, Bentchikou M, Gabrion J, Gallo-bona N, Gauquelin-koch G, Gharib C, Allevard A M. Presence of atrial natriuretic peptide in two desert rodents: comparison with rat. Peptides, 1998, 19(4), 715-726. PMID:9622027

[5] Saadi L, Lebaili N, Effect of a water-rich diet on adrenal zona glomerulosa in Gerbillus tarabuli. C. R. Biologies 335, 2012, 96-102. http://dx.doi.org/10.1016/j.crvi.2011.12.002

[6] Mote R N., Histophysiological alterations in adrenal glands of rat under industrial stresses. Int J Biol Med Res, 2010, 1(4), 287-290.

[7] Dallman M F, Akana S F, Scribner K A, Bradbury M J, Walker C D, Strack A M, Cascio C S. Stress feedback and facilitation in the hypothalamo-pituitary-adrenal axis.

J Neuroendocrinol. 4,1992, 517-526.PMID:21554636DOI:10.1111/j.1365-26.1992.tb00200.x

[8] McCarty R., Sympathetic-adrenal medullary and cardiovascular responses to acute cold stress in adult and aged rats. J. Autonomic Nervous System 12, 1985, 15-22. PMID:3980919

[9] Kvetnansky R, Lu X, Ziegler M G. Stress-triggered changes in peripheral catecholaminergic systems. Adv Pharmacol., 68, 2013, 359-97. doi: 10.1016/B978-0-12411512-5.00017-8.

[10] Jones C W, Pickering BT. Comparison of the effects of water deprivation and sodium chloride imbibition on the hormone content of the neurohypophysis of the rat. J. Physiol, 203, 1969, 449-458. PMID:5796472 PMCID:PMC1351455 
[11] Dai WJ, Yao T. Effects of dehydration and salt-loading on hypothalamic vasopressin mRNA level in male and female rats Brain. Research, 676, 1995, 178-182. PMID:7796167

[12] Kondo N, Arima H, Banno R, Kuwahara S, Sato I, Oiso Y. Osmoregulation of vasopressin release and gene transcription under acute and chronic hypovolemia in rats. Am $\mathbf{J}$ Physiol Endocrinol Metab., 2004, 286 (3), 37-46. PMID:14613925 DOI:10.1152 /ajpendo. 00328.2003

[13] Summy-Long J Y, Hu S, Pruss A, Chen X, Phillips T M. Response of interleukin-1beta in the magnocellular system to salt-loading. $\mathrm{J}$ Neuroendocrinol.,2006,8(12), 926-37. PMID:17076768 DOI:10.1111/j.1365-2826.2006.01490.x

[14] Salter-Venzon D, Watts A G. The role of hypothalamic ingestive behavior controllers in generating dehydration anorexia: a Fos mapping study. Am J Physiol. Regul. Integr. Comp. Physiol., 295, 2008, R1009-R1019. DOI:10.1152/ajpregu.90425.2008

[15] Salter-Venzon D, Watts A G. Site-specific attenuation of food intake but not the latency to eat after hypothalamic injections of neuropeptide $\mathrm{Y}$ in dehydrated-anorexic rats. Am $\mathbf{J}$ Physiol. Regul. Integr. Comp. Physiol., 297, 2009, R1813-R1821. PMID:19741057 PMC2803617 DOI:10.1152/ajpregu.00116.2009

[16] Laalaoui A, Fèvre-Montange M, Ahboucha S, Gamrani H. Proopiomelanocortin in the arcuate nucleus of the rodent Meriones shawi: Effects of dehydration. acta histochemica, 113,2011, 369-374. DOI:10.1016/j.acthis.2010.01.011

[17] Takei Y, Bartolo R C, Fujihara H, Ueta Y. Donald J A. Water deprivation induces appetite and alters metabolic strategy in Notomys alexis: unique mechanisms for water production in the desert. Proc. R. Soc. B 279, 2012, 2599-2608. Doi:10.1098/rspb.2011.2627

[18] Kutscher C L. Hematocrit, plasma osmolality, and plasma protein concentration as stimators of plasma volume in hooded rats during food and water deprivation. Physiology \& Behaviour,1971,7(2). 283-285. http://dx.doi.org/10.1016/0031-9384(71)90302-7

[19] Capponi A M. Regulation of cholesterol supply for mineralocorticoid biosynthesis. Trends Endocrinol Metab. 13, 2002, 118-121. PMID:11893525

[20] Bollag W, Kent P, White S,Wilson M V, Isales C M, Calle R A Phorbol ester increases mitochondrial cholesterol content in NCI H295R cells. Mol. Cell Endocrinol 296, 2008, 53 57. DOI:10.1016/j.mce.2008.08.022

[21] Dohanics J, krisztiina J, Kovacs K J, folly G, Makara G B. Long-term salt loading impairs pituitary responsiveness to ACTH secretagogues and stress in rats. Peptides, 11, 1998, 59-63. PMID: 2160653 
[22] Petrovic-Kosanovic D, Milosevic M C, Budec M, Koko V. Effect of acute heat stress on rat adrenal medulla - a morphological and ultrastructural study. Cent. Eur. J. Biol, 2012, 7(4), 603- 610 .

[23] Chowdrey H S, Jessop D S, Patel H, Lightman S L. Altered adrenocorticotropin, corticosterone and oxytocin responses to stress during chronic salt load. Neuroendocrinology. , 1991, 54(6), 635-638. PMID:1664502

[24] Wotus C, Arnhold M M, Engeland W C. Dehydration-induced drinking decreases Fos expression in hypothalamic paraventricular neurons expressing vasopressin but not corticotropinreleasing hormone. American Journal of Physiology - Regulatory, Integrative and Comparative Physiology, 292 (3), 2007, R1349-R1358. DOI: 10.1152/ajpregu.00304.2006

[25] Stallone J N, Braun J E. Regulation of plasma antidiuretic hormon in the dehydrated Kangaroo rat (Dipodomys spectabilis M.). Gen. Comp. Endocinol. 69, 1988, 119-127. PMID:3360285

\section{How to cite this article:}

Dekar-Madoui A, Aouichat S. Touati H and Ouali-Hassenaoui S. Chronic dehydration affects hydroelectrolytic equilibrium and adrenal gland morphology in wistar rat: comparison with gerbillus tarabuli. J. Fundam. Appl. Sci., 2017, 9(2), 897-907. 